\title{
Effects of music therapy on patients with dementia: A systematic review
}

\author{
Liridon Avdylaj, Ines Dujc \\ Izola General Hospital, Izola, Slovenia \\ liridon.avdylaj@gmail.com; ines.dujc@gmail.com
}

\begin{abstract}
Introduction: A high percentage (20\% to $40 \%$ ) of residents in nursing homes care and patients in acute hospitals suffering from dementia develop neuropsychiatric symptoms such as anxiety, depression, agitation, apathy and delusions. Neuropsychiatric symptoms are complex, stressful and challenging to manage, which increase caregiver's burden and the cost associated with dementia care. This systematic literature review aims to investigate the effects of music therapy on neuropsychiatric symptoms of patients with dementia. Methods: A literature search was performed in databases: MEDLINE, Wiley Online Library, CINHAL and ScienceDirect. The search keywords included dementia, music therapy, neuropsychiatric symptoms, anxiety, depression. The search was limited to scientific articles; only articles in English language; only systematic reviews; articles published from January 2011 to January 2021; articles with full text available; articles about residents, who were clinically diagnosed with dementia; articles on study intervention: music therapy; outcomes of study: reported at least one effect of music therapy on neuropsychiatric symptoms; reviews were required to have an AMSTAR rating of five points or greater. Results: We screened 3257 titles, only 12 articles, involving in total 5.978 patients, met the inclusion criteria for review. Overall, the studies showed that music therapy has a significant impact on decreasing neuropsychiatric symptoms of people with dementia. Some of studies found out that there were no significant improvements on cognition or daily functioning and the results on quality of life were ambiguous. Discussion and conclusions: Music therapy is beneficial and improves neuropsychiatric symptoms of people with dementia, therefore it could be a powerful treatment strategy in the future. However further randomized studies are still needed.
\end{abstract}

Keywords: dementia, music therapy, neuropsychiatric symptoms, depression, anxiety. 


\section{Introduction}

Dementia is a syndrome caused by a brain disease that can be chronic or progressive (World Health Organization, 2020). A large proportion (from $20 \%$ to $40 \%)$ of residents of nursing homes and patients in hospitals suffering from dementia develop neuropsychiatric symptoms, such as violent behavior, agitation, wandering, socially inappropriate behavior, eating disorders, anxiety, depression, apathy, insomnia, delusions, misidentification, and hallucinations (Aarsland, 2020).

Demographic aging is a global process resulting from improved healthcare over the last century. There are more than 10 million new cases of dementia worldwide each year, i.e. one new case every 3.2 seconds (Alzheimer's disease international, 2020; Alzheimer's Association, 2021).

Dementia is also a major economic burden because treatment costs are high. Treatment includes costs attributable to informal care (unpaid care for family and others), direct costs of social care (provided by professionals), and direct costs of healthcare (cost of treating dementia and other conditions in primary and secondary care) (Castro et al., 2010; Gustavsson et al., 2010).

The treatment of patients with dementia is holistic. Both pharmacological and non-pharmacological treatments are important. However, there is now a wide range of non-pharmacological strategies to treat neuropsychiatric symptoms. Among these strategies, music therapy is worth mentioning. According to the World Federation for Music Therapy, music therapy is "the use of music and/or musical elements (sound, rhythm, melody, and harmony) by a qualified music therapist, with a client or group, in a process designed to facilitate and promote communication, relationships, learning, mobilization, expression, organization, and other relevant therapeutic objectives to meet physical emotional, mental, social and cognitive needs". Some studies indicated a beneficial effect on reducing the anxiety of patients with dementia (Svansdottir and Snaedal, 2006, Goddaer and Abraham, 1994; Moroi et al., 2008; Nomi et al., 2005; Tabloski et al., 1995; Tsuchiya, 2003) and a few studies also indicated moderate increase a cognitive function (Miura et al., 2005). On the other hand, some studies reported that music therapy did not have a significant effect on agitated behaviors in those with dementia (Sung et al., 2012).

\section{Methods}

A literature search was performed in databases.

\section{Search strategy and selection criteria}

A literature search was conducted in following databases: MEDLINE, Willey Online Library, CINHAL and ScienceDirect. The search keywords included dementia, music therapy, neuropsychiatric symptoms, anxiety, depression. Databases were searched using the Boolean operators to find the results (dementia AND music therapy AND neuropsychiatric symptoms OR anxiety OR depres- 
sion). The search was limited to scientific articles; only articles in English language; only systematic reviews; articles published from January 2011 to January 2021; articles with full text available; articles about residents who were clinically diagnosed with dementia; articles on study intervention: music therapy; outcomes of study: reported at least one effect of music therapy on neuropsychiatric symptoms; reviews were required to have an AMSTAR rating of five points or greater (Table 1 ).

Table 1: Inclusive and exclusive criteria

\begin{tabular}{|c|c|c|}
\hline Criteria & Inclusion criteria & Exclusion criteria \\
\hline Topic & $\begin{array}{l}\text { Effect of music therapy on de- } \\
\text { creasing neuropsychiatric symp- } \\
\text { toms of patients with dementia }\end{array}$ & $\begin{array}{l}\text { Other types of therapy on de- } \\
\text { creasing neuropsychiatric symp- } \\
\text { toms of patients with dementia }\end{array}$ \\
\hline Population & $\begin{array}{l}\text { Residents or patients who were } \\
\text { clinically diagnosed with de- } \\
\text { mentia }\end{array}$ & $\begin{array}{l}\text { Residents or patients with other } \\
\text { pathologies or matters }\end{array}$ \\
\hline Types of study & Only systematic reviews & Other study design \\
\hline Time frame & $1.1 .2011-1.1 .2021$ & Published before 1.1. 2011 \\
\hline Language & English only articles & Articles in other languages \\
\hline Available in electronic databases & articles with full text available & Incompletely accessible articles \\
\hline Outcomes & $\begin{array}{l}\text { reported at least one effect of mu- } \\
\text { sic therapy on neuropsychiatric } \\
\text { symptoms }\end{array}$ & No outcomes/unclear effect \\
\hline Rating tool & $\begin{array}{l}\text { Five points or greater by AM- } \\
\text { STAR }\end{array}$ & Less than five points by AMSTAR \\
\hline
\end{tabular}

Legend: AMSTAR-A Measurement Tool to Assess systematic reviews.

\section{Study identification and selection}

Without the use of pre-defined exclusion criteria, we obtained 9.327 titles. Of these, the most articles were in the Medline database, namely 3.263, the second database with the most articles was Willey Online Library 1.054 articles, in the CINHAL there were 872 articles, and the least results were in the ScienceDirect database, there were 520 articles. After applying such as time limit, removal of duplicates, full availability of text and articles in English, the number of results was reduced to 549 articles. We further removed an additional 127 articles based on analysis of article titles and/or abstracts due to population, which did not include residents or patients who were clinically diagnosed with dementia, thus removing and additional 100 articles. In addition, 64 additional articles were excluded because we could not accurately understand or the effect of music therapy was unclear. We removed an additional 15 articles because authors use other types of non-pharmacological therapy on decreasing neuropsychiatric symptoms of patients with dementia. At finally phase we evaluated twenty articles with a Measurement Tool to Assess systematic review (AMSTAR). Only twelve articles met other inclusion criteria and get more than five points or greater by AMSTER. 
Twelve articles included in the systematic review of the literature met all the set inclusion criteria. Articles that were in line with the purpose and goal of our systematic review were evaluated with a Measurement Tool to Assess systematic review (AMSTAR) (Table 2). A total of 5,978 patients participated in all studies included in our review. The PRISMA approach () was used to show the course of the literature review (Figure 1) (Moher et al., 2015). We further imported the results into the Zotero program, which is a research tool that also enables the organization, storage of resources, management and citation of our references.

\section{Results}

We identified and analysed 12 articles (Ueda et al., 2013; Ing-Randolph et al., 2015; Fusar-Poli et al., 2018; Gomez-Romero et al., 2017; Sherriff et al., 2017; Rezende Alexio et al., 2017; Zhang et al., 2016; Mercadal-Brotons and Alcantara-Silva., 2019; Bartfy et al., 2019; Li et al., 2019; Long Lam et al., 2020; Morales et al., 2020) showed on (Table 2).

\section{Table 2: Overview of studies}

\begin{tabular}{|c|c|c|c|c|c|}
\hline Reference & Type of study & Study goal & Sample size & Research findings & AMSTAR \\
\hline Ueda et al., 2013 & $\begin{array}{l}\text { A systematic } \\
\text { review }\end{array}$ & $\begin{array}{l}\text { Investigate the } \\
\text { effects of music } \\
\text { therapy on be- } \\
\text { havioural and } \\
\text { psychological } \\
\text { symptoms, cog- } \\
\text { nitive function, } \\
\text { and activities } \\
\text { of daily living } \\
\text { in patients with } \\
\text { dementia. }\end{array}$ & 617 & $\begin{array}{l}\text { The effect of therapy is } \\
\text { effective for the man- } \\
\text { agement of behav- } \\
\text { ioural and psychologi- } \\
\text { cal symptoms. }\end{array}$ & $11 / 11$ \\
\hline $\begin{array}{l}\text { Ing- Randolph } \\
\text { et al., } 2015\end{array}$ & $\begin{array}{l}\text { Systematic } \\
\text { review }\end{array}$ & $\begin{array}{l}\text { To review the } \\
\text { using group } \\
\text { music interven- } \\
\text { tion to reduce } \\
\text { dementia-asso- } \\
\text { ciated anxiety, } \\
\text { the delivery of } \\
\text { such interven- } \\
\text { tions. }\end{array}$ & $\begin{array}{l}361 \text { people clin- } \\
\text { ically diagnosed } \\
\text { with demen- } \\
\text { tia, the age of } \\
\text { subjects ranged } \\
62.7-99 \text { years }\end{array}$ & $\begin{array}{l}\text { Group music inter- } \\
\text { vention to treat de- } \\
\text { mentia-associated } \\
\text { anxiety is a promising } \\
\text { treatment. However, } \\
\text { the small number of } \\
\text { studies and the large } \\
\text { variety in methods } \\
\text { and definitions lim- } \\
\text { it our ability to draw } \\
\text { conclusions. }\end{array}$ & $9 / 11$ \\
\hline
\end{tabular}


The aim is to

ascertain the

conclusions of scientific publi-

Gomez-Romero A systematic et al., 2017 review

cations regarding the benefits of music therapy on behavioural problems elderly patients

with dementia.

To analysed the efficacy of music therapy in elderly demen-

Zhang et al., 2016

A systematic review of literature tia patients, and

if so where music therapy can be used at firstline non-pharmacological treatment.

The effect of music therapy on cognitive functions in patients with dementia.

$\begin{array}{ll}2018 & \begin{array}{l}\text { review of liter- } \\ \text { ature }\end{array}\end{array}$

Rezende Alexio et al., 2017

A systematic review of literature
Assessing the efficacy of music therapy in the neuropsychiatric symptoms of people with dementia.
404 subjects diagnosed with dementia.
Music therapy is ben-

eficial and improves behaviour disorders, anxiety and agitation $9 / 11$ in subjects diagnosed with dementia.
1757 adults with dementia
The meta-analysis suggested that music therapy had positive effects on disruptive behaviour and anxiety and positive trend for cognitive function, depression and quality of life.
$11 / 11$

It is possible to affirm that the positive effect of music therapy on $9 / 11$ cognitive impairments in dementia.

\section{0}

In general, studies in-

641 elderly dicated the efficacy of with uncatego- music therapy on the rized demen- decline of depression, tia, $A D$, vascu- agitation and anxiety. lar dementia, There were heterogemixed dementia neity of interventions, in mild, mod- methodological deerate and sever sign and instruments stages. of evaluation among studies.

Music delivery was

To establish whether music therapy improves neu-

Sherriff et al.,

A systematic review of literature adults with de- ropsychiatric symptoms in mentia and/or delirium in the general hospital. feasible and have a positive effect on some aspects of neuropsychiatric symptoms in various set-

239 patients clinically diagnosed with dementia. tings, but the studies was generally small at high risk of bias and did not use recognized frameworks for evaluating complex interventions. 
Determine the effectiveness of music therapy on reduc-

Hui-Chi Li et A systematic real., 2019 view of literature ing depression for people with dementia during different intervention intervals.
Music therapy interventions can effectively reduce people depression in people with dementia. The importance of music therapists in music therapy interventions.
The results of the sources analyzed show that active music therapy seems to be safe

To provide clinical recommendation regarding music therapy interventions on patients with non-Alzheimer disease dementia.
136 patients. 15 patients were diagnosed with dementia. and effective treatment for all tyoes of dementia. However, it is recommended that future studies contemplate and highlight

the diversity of symp-

toms and course of the disease of the different types of demen$10 / 11$ $\begin{array}{ll}\text { tons and Alan- } & \text { view } \\ \text { tara-Silva., 2019 } & \text { ature }\end{array}$

A systematic retia in order to identify and better understand the music therapy interventions best suited for each of them

Overall, the studies showed a significant

To examines the effects of music therapy

Bartfay et al., A systematic re- on behaviourview of liter- al psychologiature cal symptoms of dementia and the quality of life.
Approximately 1872 patients clinically diagnosed with dementia. impact on mitigating agitation, reducing BPSD and improving memory, cognition, QOL, and decreasing anxiety and symptoms associated with depression.

Music therapy could be a powerful treatment strategy. It is necessary to developed clinical tri-

Effect of music therapy on cognitive function, quality of Morales et al., A systematic review of literature life, and/or depressive state in people living with dementia. als aimed to design standardized protocols depending on the nature or stage of dementia so that they can be applied together with current cognitive-behavioural and pharmacological therapies. 


\begin{tabular}{llll} 
& & $\begin{array}{l}\text { Effects of mu- } \\
\text { sic therapy on } \\
\text { patients with } \\
\text { dementia to } \\
\text { evaluate its po- } \\
\text { tential benefits } \\
\text { on dementia. }\end{array}$ & No data \\
2020 & $\begin{array}{l}\text { Music therapy could } \\
\text { improve verbal fluen- } \\
\text { cy and reduce anxie- } \\
\text { ty, depression, and ap- } \\
\text { athy to patients living } \\
\text { view of liter- } \\
\text { ature }\end{array}$ & $\begin{array}{l}\text { with dementia. There } \\
\text { dose not appear to be } \\
\text { proven benefits on } \\
\text { memory, daily func- } \\
\text { tion, or overall quali- } \\
\text { ty of life }\end{array}$ \\
\hline
\end{tabular}

\section{Discussion}

Nowadays, there is a growing incidence of this disease in the population all around the world, and, therefore, it is important to develop treatments and activities to relieve its symptoms. To reach that assumption, we performed this overview which identified 12 systematic reviews including 228 studies reporting on outcomes of music therapy on at least one neuropsychiatric symptom to patients with dementia. These reviews addressed components that are important for this intervention to be successful, like for example range of different types of music therapy, the intervention length, the number of sessions per week, and the person who conducted music therapy.

Some of the analyzed studies found out that music therapy can alleviate anxiety and depression. Gomez-Romero et al., 2017, found that different types of music therapy (active technique, passive listening, or combined technique) are beneficial for improving anxiety. The results of a study by author Ueda et al., 2013 indicate that music therapy reduced anxiety and depression in people with dementia. However, they were unable to clarify what type of music therapy. Regarding the effects of the intervention type, the singing intervention seemed to produce moderate effects on behavior and anxiety. The listening intervention might produce somewhat more effects on the outcomes of behavior, depression, and anxiety. In the study by Alexio et al., 2017, receptive "relaxation" music therapy is a method that probably better reduces neuropsychiatric symptoms. Studies of authors Zhang et al., 2016, and Long Lam et al., 2020, also showed that music therapy had positive effects on disruptive behavior and anxiety but also a positive trend for cognitive function, depression, and quality of life.

A systematic review from author Long Lam et al., 2020, showed that the effect of music therapy on patients living with dementia suggested significant improvements in verbal and language fluency, alleviation of BPSD including anxiety and depression and reduced levels of apathy. These findings are generally in line with previous reports on the potential benefits of music therapy in improving the behavioral symptoms in patients living with dementia (Zhang et al., 2016; Gomez-Romero et al., 2017). However, this study suggests that the music therapy field significantly improves the overall aspects of cognition (such as 
memory, orientation, and registration), agitation, daily functioning, and the quality of life living with dementia. A systematic review with meta-analyses from authors Fusar-Poli et al., 2018, aimed at providing an overview of the possible effects of music therapy on cognitive functions in patients with dementia. Results confirm the conclusions of previous reviews which did not find any significant improvement in global cognition (Chang et al., 2015; Lie et al 2015; Ueda et al., 2013). They did also not find any positive effect of music therapy on domains like cognitive functions, such as attention, language, memory, and perceptual-motor skills.

A study by Li et al., 2019, showed that the intervention length and number of sessions per week of music therapy is very important to reduced depression of people with dementia. The meta-analysis revealed that music therapy was significantly associated with decreasing the degree of depression for medium-term intervention (six to 12 weeks). No significant differences in depressive levels were found between music therapy and control groups in short-term interventions (three or four weeks). The effects of medium-term music therapy may contribute to improved depression in people with dementia while shortterm intervention may not. Another similar meta-analysis study suggested that short-term music therapy might not be able to improve cognitive function for people with dementia (Li HC et al., 2015).

The definition of music therapy specifies that sessions must be guided by a qualified music therapist. A majority of analyzed studies showed that the involvement of music therapists significantly reduced neuropsychiatric symptoms (Li et al., 2019; Gomez-Romero et al., 2017; Ueda et al., 2013; Fusar-Poli et al., 2018; Alexio et al., 2017; Sherriff et al., 2017).

Our systematic review includes a relatively large number of subjects and studies. Therefore, we can summarize that music therapy has a significant impact on decreasing neuropsychiatric symptoms of people with dementia. Some studies found out that there were no significant improvements in cognition or daily functioning and the results on quality of life were ambiguous.

\section{Conclusions}

Music therapy is beneficial and improves neuropsychiatric symptoms of people with dementia. Therefore, it could be a powerful treatment strategy in the future. However further randomized studies are still needed.

\section{References}

AARSLAND, D., 2020. Epidemiology and Pathophysiology of Dementia-Related Psychosis. J Clin Psychiatry. vol. 81, no. 5, pp. 1-10.

ALZHEIMER'S DISEASE INTERNATIONAL, n. d. Dementia statistics [online]. [viewed 10 June 2021]. Available from: https://www.alzint.org/ about/dementia-facts-figures/dementia-statistics/ 
BARTFAY, W.-J., ALI M., HORSBURGH, S., DUFF-WOSKOSKY, A., and EARLE, J., 2019. A Systematic Review of the Literature for the Effects of Music on Dementia Patients. Gerontology \& Geriatric Research. vol. 1, no. 1, pp. 1-12.

CASTRO, D.-M., DILLON, C., MACHNICKI, G. and ALLEGRI F.-R., 2010. The economic cost of Alzheimer's disease: Family or public health burden?. Dement Neuropsychol. vol. 4, no. 4, pp. 262-267.

FUSAR-POLI, L., BIELENINIK, L., BRONDINO, N., XI JING, C. and GOLD, C., 2018. The effect of music therapy on cognitive functions in patients with dementia: a systematic review and meta-analysis. Aging and mental health. vol. 22, no. 9, pp. 1103-112.

GODDAER, J. and ABRAHAM I.- L. 1994. Effects of relaxing music on agitation during meals among nursing home residents with severe cognitive impairment. Arch Psychiatr Nurs. vol. 8, no. 3, pp. 150-158.

GOMEZ ROMEROA, M., JIMENEZ PALOMARES, M., RODRIGUEZ MANSILLAC, J., FLORES NIETOC, A., GARRIDO ARDILA, E.-M. and GONZALEZ LOPEZ ARZA, M.-V., 2017.Benefits of music therapy on behaviour disorders in subjects diagnosed with dementia: A systematic review Neurología. no. 32, pp. 253-263.

GUSTAVSSTON, A., JONSSON, L., RAPP, T., REYNISH, E., OUSSET, P.-J., ANDRIEU, S., CANTET, C., WINBLAD, B., VELLAS, B. and WIMO, A., 2010. Differences in resource use and costs of dementia care between European countries: baseline data from the ICTUS study. J Nutr Health Aging

HUI-CHI, LI., HSIU HUNG, W., CHU YUN, L., TAI BEEN, C., YU HUA, and I, L., 2019. The effect of music therapy on reducing depression in people with dementia: A systematic review and meta-analysis. Geriatric Nursing. no. 40, pp. $510-516$.

ING-RANDOLPH, A.-R., PHILLIPS, R.-L. and WILLIMAS, B.-A., 2015. Group music interventions for dementia-associated anxiety: A systematic review. International Journal of Nursing Studies. no. 52, pp. 1775-1784.

LONG LAM, H., WAI TAK, V.-L., ISMAIL, L. and WONG, Y.-W., Effects of Music Therapy on Patients with Dementia-A Systematic Review. Geriatrics. vol. 5 no. 62, pp. 1-14.

MERCADAL BROTONS M. and ALCANTARA SILVA, T.-R., 2019. Music Therapy for Non-Alzheimer's Disease Dementia: A systematic review. $J$ Alzheimers Neurodegener. vol. 5, no, 1, pp. 1-10.

MIURA, H., KANAYAMA, Y., MOGI, N. and ENDO, H., 2005. Effect and significance of music therapy on elderly persons with mild dementia. Japanese Journal of Music Therapy, vol. 5 pp. 48-57. 
MORENO MORALES, C., CALERO, R., MORENO MORALES, P. and PINTADO, C., 2020. Music Therapy in the Treatment of Dementia: A Systematic Review and Meta-Analysis. Front. Med. vol. 7 pp. 1-11.

MOROI, K., YAGUNCHI, K., YASUNAGA, A., OOKUBO, T. and ABE, A., 2007. A sudy of the effects of music therapy fort he elderly with mild-dementia. Tokai University, School of Health Sciencs. vol. 12 pp. 7-14.

NOMI, A., HOSOYA, M., MIHARA, Y., KOTOH, A. and MIHARA, E., 2005. Effects of music therapy for dementia: reducing behavioral problem. Tsusyo Care. vol. 3, 63-68.

REZENDE ALEIXO, M.-A., SANTOS, L.-R. and NASCIMENTO DOURADO, M.-C., 2017. Efficacy of music therapy in the neuropsychiatric symptoms of dementia: systematic review. Bras Psiquiatr. vol. 66, no. 1, pp. 5261.

SHERRIFF, C., MATHEWS, J., REYNISH, E.-L. and SHENKIN, S.-D., 2017. Music Therapy for Neuropsychiatric Symptoms in the General Hospital: a systematic literature review. Music \& Medicine. vol. 9, no. 4, pp. 217-226.

SUNG, H., LEE, W., LI, T. and WATSON, R., 2012 A group music intervention using percussion instruments with familiar music to reduce anxiety and agitation of institutionalized older adults with dementia. Int J Geriatr Psychiatry. no. 27, pp. 621-627.

SUNG, H.C., LEE, W.L., LI, T.L. and WATSON, R., 2012. A group music intervention using percussion instruments with familiar music to reduce anxiety and agitation of institutionalized older adults with dementia. International Journal of Geriatric Psychiatry, vol. 27, no. 6. pp. 621-627.

SVANSDOTTIR, H.-B. and SNAEDAL, J. 2006. Music therapy in moderate and severe dementia of Alzheimer's type: a case-control study. Int Psychogeriatr. vol. 18, no. 4, pp. 613-621.

TABLOSKI, P.A., MCKINNON-HOWE, L. and REMINGTON, R., 1995. Effect of calming music on the level of agitation in cognitively impaired nursing home residents. American Journal of Alzheimer's Disease and Other Dementias, vol. 8 pp. 10-15.

TOMOMI, U., YOSHIMI, S., MAI, S. and SHIN INCHI, I., 2013. Effects of music therapy on behavioral and psychological symptoms of dementia: A systematic review and meta-analysis. Ageing Research Reviews. no. 12, pp. 628-641.

TSUCHYIA, J.-K., BYRNE, M. and MORTENSEN, B.-P., 2003. Risk factors in relation to an emergence of bipolar disorder: a systematic review. Bipolar Disord. vol. 5, no. 4, pp. 231-242. vol. 14, no. 8, pp. 648-654.

WORLD HEALTH ORGANIZATION., 2021. Dementia [online]. [viewed o4 september 2021]. Available from: https://www.who.int/news-room/factsheets/detail/dementia 
YINGSHI, Z., JIAYI, C., LI, A., FUHAI, H., TIANSHU, R., HONGDA, M. and QINGCHUN, Z. 2017. Does music therapy enhance behavioral and cognitive function in elderly dementia patients? A systematic review and meta-analysis. Ageing Research Reviews. no. 35, pp. 1-12.

ZHANG, Y., CAI, J., AN, L., HUI, F., REN, T., MA, H. and ZHAO, Q., 2016. Does music therapy enhance behavioral and cognitive function in elderly demenita patients? A systematic review and meta-analysis. Ageing Research Reviews, vol. 35, no. 2017. pp. 1-11. 